\title{
The Knowledge of Medical Professionals from Selected Hospitals in the Lubelskie Province about Diagnosis-Related Groups Systems
}

\author{
Petre Iltchev $^{1}$, Aleksandra Sierocka ${ }^{2}$, Sebastian Gierczyński ${ }^{1}$, \\ Michał Marczak ${ }^{1}$ \\ ${ }^{1}$ Chair of Health Care Policy, Medical University of Lodz, Poland \\ ${ }^{2}$ K. Jonscher Hospital in Lodz, Poland
}

\begin{abstract}
Health information technology (IT) in hospitals can be approached as a tool to reduce health care costs and improve hospital efficiency and profitability, increase the quality of healthcare services, and make the transition to patient-centered healthcare. A hospital's efficiency and profitability depends on linking IT with the knowledge and motivation of medical personnel. It is important to design and execute a knowledge management strategy as a part of the implementation of IT in hospital management. A Diagnosis-Related Groups (DRG) system was introduced in Poland in 2008 as a basis for settlements between hospitals and the National Health Fund (NHF). The importance and role of a DRG system in management of healthcare entities was emphasized based on a survey of medical professionals from two hospitals in the Lubelskie province. The goal of a survey is to assess the knowledge of medical professionals about the DRG system and how the medical personnel uses the DRG system in order to achieve the strategic goals of the organization. A newly developed survey was used to assess the medical personnel's knowledge of DRG, using 12 closed and 5 open questions. The survey was conducted on 160 medical employees from two hospitals in the Lubelskie province. In conclusion, medical personnel's DRG knowledge unambiguously contributes to reducing hospital costs and increasing profitability. The DRG related knowledge enables personnel to obtain value from data by applying DRG data-driven decisions.
\end{abstract}

\section{Introduction}

Implementation of DRG in Poland forced a change in hospitals to occur. The biggest challenge in implementing DRG reporting is to understand its vast impact on hospital operations, costs, and profitability. DRG directly impacts each medical professional from nurses to coders to physicians. In Poland, the labor costs in the hospital budget are between 40 and 70 percent. Optimization of management of medical staff, as far as their cost culture, can have an impact on a hospital's efficiency and debt. Staff engagement 
in costs is key for hospital efficiency and profitability. DRG is a way to improve the hospital costs culture. Better collaboration between coders, nurses and physicians, a culture of team work, can overcome barriers hampering hospital efficiency improvements.

Health information technology (IT) in hospitals can be approached as a tool to reduce health care costs and improve hospital efficiency and profitability, increase the quality of healthcare services, and make the transition to patient-centered healthcare. The hospital efficiency and profitability depends on linking IT with the knowledge and motivation of medical personnel. The success of using IT applications is impacted by implementation and the knowledge of users. You cannot separate initiatives designed to increase the knowledge and motivation of the medical personnel from the implementation and use of IT in hospitals. Without proper knowledge investments, medical informatics will not deliver the expected results. It is important to design and execute a knowledge management strategy as a part of the implementation of IT in hospital management. The Diagnosis-Related Groups (DRG) related knowledge survey is the first phase of a project for knowledge management. A DRG system was introduced in Poland in 2008 as a basis for settlements between hospitals and the National Health Fund (NHF). DRG is a combination of medical and cost approaches. Five years after the introduction of the DRG system in Poland, we assume that it should form the basis for auditing and strategically managing a hospital. DRG system knowledge among the medical personnel is important for the implementation of the hospital's strategy and for its financial results. The personnel of public hospitals should be interested in their positive financial results, especially taking article 59 of the Act on Medical Activity (Ustawa z dnia 15 kwietnia 2011 r. o działalności leczniczej, 2011) into account. Pursuant to article 59, "1. An independent public health care institution will cover on its own its negative financial result ... 4. In case the negative financial result is not covered using a method established in clause 2 , the entity which created the institution within 12 months will issue a decree, regulation or a resolution to change the organisational and legal form or to dissolve the independent public health care institution".

In accordance with the $80 / 20$ principle, there are a few factors which ensure the effect of using a DRG system in the management of the hospital. The following are examples of key indicators that characterise the DRG system in auditing and financial management of the hospital:

a) profit from a patient,

b) profit from a medical procedure,

c) daily profit from a patient. 
Medical professionals who are aware of the role of a DRG system are able to use it better in the hospital management process and to take it into account when making medical decisions. Figure 1 presents the role of the analysis of the medical personnel's DRG system knowledge in the hospital management process.



Figure 1. The place of employees' DRG system knowledge in the hospital management process

Investment in the DRG system training of medical staff can be very profitable for hospitals (Walker et al., 2010). A few examples of case study topics are provided by Busse et al. (2011), Minich-Pourshadi (2011) and Walker et al. (2011). Knowledge analysis related to a DRG system is fundamental for successful DRG implementation and realization of profits from the contract with the NHF. This process can be helped by applying the work of McKenzie et al. (2003). Modelling hospital financial result with the use of DRG can be based on the works of Wike et al. (2011) and HOPE - European Hospital and Healthcare Federation (2006). For an example of pharmaco-economical simulations, the work of Wike et al. (2010) can be consulted. Analysis of the use of information related to DRG in the process of making strategic, tactical and operational decisions, as described by LaValle et al. (2010), is fundamental for giving hospitals a competitive advantage in the new economic environment. Analyses of the necessary changes 
in IT systems are crucial for hospital operational effectiveness (ECRI Institute, 2012).

The development of the DRG system should be understood to be an element of a widely understood hospital IT strategy (HealthLeaders Media, 2010). Thus, it is very important to establish how the DRG system support infrastructure will be integrated with the remaining IT systems used in the hospital. It is also important to answer the question of what impact the changes to the DRG system will have on the hospital's finances (Busse et al., 2011, Charlesworth et al., 2012, HealthLeaders Media, 2011).

\section{Data - Survey Results and Interpretation}

The study was conducted among the medical personnel in two hospitals in the Lubelskie province - the Bychawa District Hospital and Cardinal Stefan Wyszyński Provincial Specialist Hospital - within the January April 2013 period. The structure of surveys received from the study participants (160) is as follows in Table 1.

Table 1. Participants in the study, as per profession and medical entity

\begin{tabular}{|l|c|c|c|}
\cline { 2 - 4 } \multicolumn{1}{c|}{} & $\begin{array}{c}\text { Bychawa District } \\
\text { Hospital }\end{array}$ & $\begin{array}{c}\text { Cardinal Stefan } \\
\text { Wyszyński Provincial } \\
\text { Specialist Hospital } \\
\text { in Lublin }\end{array}$ & Total \\
\hline Head of a Hospital Ward & 2 & 8 & 10 \\
Physician & 8 & 20 & 28 \\
Nurse & 50 & 50 & 100 \\
Medical statistician & 3 & 9 & 12 \\
Medical secretary & 3 & 7 & 10 \\
\hline
\end{tabular}

The provided answers to the survey show that in order to improve their financial results in a manner that does not require significant investments, the hospitals should commence by organising training courses. Internal courses are an investment that will bring the highest return. Small financial outlays enable the general DRG system knowledge level for the entire medical personnel to increase as well as its impact on the hospital's financial result. Indicating the role of the system, the sources of information, the connection of efficiency, cost-effectiveness and effectiveness oriented thinking with responsibility, in addition to a motivating system, are the keys 
to increasing the operational effectiveness of hospitals. This connection is presented in a graphic manner in the Figure 2.

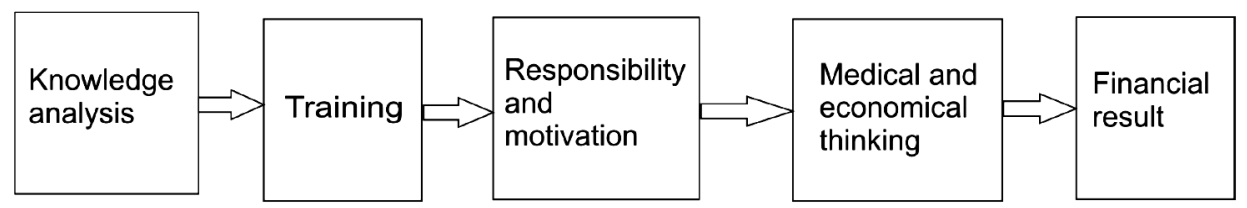

Figure 2. The medical personnel economic awareness increase cycle

For $74 \%$ of employees responding to the survey, no answer and the opinion that the DRG system has no impact on their work means that they are not able to assess the economic results of the medical decisions they make. The lack of economic knowledge of the medical personnel in question means that they are not aware that the results of the medical decisions taken may frequently result in a negative financial result for a specific medical case. The sum of financial results of individual cases (patients) creates the financial result of the entire hospital. The change of approach and organisation of work is important, to ensure that the medical personnel do not consider the DRG system to be an obstacle. The awareness of the economic impact of the DRG system on the hospital's financial result, as well as the remuneration of each employee and active search for work improvement methods, may change the approach of persons who consider the use of the system to be an obstacle and make them actively use the system.

The DRG system in Poland is undergoing dynamic changes and constant development. Changes occur in illness groups, individual units, dictionaries of admittance and discharge, and finally, principles of contracting. All these changes justify the need for continuous training instead of single sessions. The answer of close to $1 / 3$ of those surveyed is even more incomprehensible in that light. This shows that the hospital management needs to engender a significant increase in awareness among the medical personnel on the importance of the DRG system for the hospital's operation and positive financial result. In addition, the selected forms of training indicate a preference among medical employees for more modern online training courses, or an on-line connection in a hospital or outside the medical institution, compared to more traditional forms of training.

If we are aiming to achieve a positive financial result in a hospital, each ward should be trying to generate profit. Otherwise, each hospital ward head will think that other wards should generate profits, instead of his or hers. As a consequence of such an approach, the hospital will probably have a negative financial result. 
A detailed analysis of responses provided by medical statisticians and key persons responsible for the execution of an NHF contract, that is, heads of hospital wards and physicians, enables better planning of actions intended to increase the use of DRG in hospital management. Table 2 presents their answers, compared to all the surveyed persons.

Table 2. Answers of key persons, compared to all the surveyed persons

\begin{tabular}{|c|c|c|c|c|}
\hline \multirow[b]{2}{*}{ Scope of the question } & \multicolumn{4}{|c|}{ Percentage of correct answers } \\
\hline & $\begin{array}{c}\text { Heads of } \\
\text { hospital wards }\end{array}$ & Physicians & $\begin{array}{l}\text { Medical } \\
\text { statisticians }\end{array}$ & All answers \\
\hline $\begin{array}{l}\text { Knowledge concerning the } \\
\text { frequency of reporting of } \\
\text { execution of contract }\end{array}$ & 100 & 29 & 100 & 25 \\
\hline $\begin{array}{l}\text { Knowledge whether the hospi- } \\
\text { tal departments are held } \\
\text { accountable pursuant to } \\
\text { income and costs of execution } \\
\text { of NHF contracts in accordance } \\
\text { with DRG }\end{array}$ & 100 & 7 & 100 & 27 \\
\hline $\begin{array}{l}\text { Knowledge whether the medi- } \\
\text { cal personnel knows the con- } \\
\text { tract values of the hospital } \\
\text { ward }\end{array}$ & 100 & 100 & 0 & 20 \\
\hline $\begin{array}{l}\text { The execution of a contract } \\
\text { is monitored pursuant to } \\
\text { a monthly reports prepared } \\
\text { using medical documentation }\end{array}$ & 100 & 86 & 17 & 24 \\
\hline $\begin{array}{l}\text { After execution of a contract } \\
\text { fewer procedures are perform- } \\
\text { ed }\end{array}$ & 100 & 54 & 0 & 5 \\
\hline $\begin{array}{l}\text { Participation in DRG-related } \\
\text { courses and training }\end{array}$ & 90 & 0 & 67 & 14 \\
\hline $\begin{array}{l}\text { The DRG system improves } \\
\text { management of the hospital's } \\
\text { finances }\end{array}$ & 60 & 18 & 58 & 16 \\
\hline $\begin{array}{l}\text { Introduction of a DRG-based } \\
\text { controlling system may } \\
\text { improve the hospital's } \\
\text { finances management }\end{array}$ & 20 & 0 & 0 & 1 \\
\hline $\begin{array}{l}\text { DRG system training for the } \\
\text { personnel will improve the hos- } \\
\text { pital's finances management }\end{array}$ & 40 & 46 & 25 & 18 \\
\hline $\begin{array}{l}\text { Self-assessment of DRG system } \\
\text { knowledge (on a satisfactory } \\
\text { level) }\end{array}$ & 100 & 18 & 83 & 18 \\
\hline
\end{tabular}




\begin{tabular}{|c|c|c|c|c|}
\hline \multirow[b]{2}{*}{ Scope of the question } & \multicolumn{4}{|c|}{ Percentage of correct answers } \\
\hline & $\begin{array}{c}\text { Heads of } \\
\text { hospital wards }\end{array}$ & Physicians & $\begin{array}{c}\text { Medical } \\
\text { statisticians }\end{array}$ & All answers \\
\hline $\begin{array}{l}\text { Courses and training were the } \\
\text { preferred form of DRG skills } \\
\text { and knowledge improvement of } \\
\text { the surveyed }\end{array}$ & 100 & 68 & 83 & 19 \\
\hline $\begin{array}{l}\text { DRG system related activities } \\
\text { do not hinder working directly } \\
\text { with a patient }\end{array}$ & 50 & 14 & 0 & 15 \\
\hline $\begin{array}{l}\text { DRG system related activities } \\
\text { are too time-consuming and } \\
\text { hinder working directly with } \\
\text { a patient }\end{array}$ & 50 & 43 & 0 & 46 \\
\hline $\begin{array}{l}\text { The surveyed think that the } \\
\text { DRG system is complicated } \\
\text { and using it requires } \\
\text { specialised knowledge }\end{array}$ & 70 & 82 & 100 & 62 \\
\hline $\begin{array}{l}\text { The DRG system is used in the } \\
\text { management of a hospital ward } \\
\text { when filling out medical } \\
\text { documentation and reports }\end{array}$ & 50 & 14 & 42 & 13 \\
\hline $\begin{array}{l}\text { The DRG system is not used in } \\
\text { the management of a hospital } \\
\text { ward }\end{array}$ & 20 & 14 & 0 & 6 \\
\hline $\begin{array}{l}\text { The motivation and wages } \\
\text { system is not connected with } \\
\text { the level of costs }\end{array}$ & 100 & 93 & 92 & 79 \\
\hline $\begin{array}{l}\text { The hospital supports new ideas } \\
\text { concerning management, work } \\
\text { organisation and process } \\
\text { improvement }\end{array}$ & 90 & 11 & 0 & 8 \\
\hline $\begin{array}{l}\text { Medical personnel needs } \\
\text { contract-related information in } \\
\text { order to better manage the hos- } \\
\text { pital / ward / patient streams / } \\
\text { processes in the area of: number } \\
\text { of contracted services, degree of } \\
\text { contract execution }\end{array}$ & 100 & 79 & 0 & 28 \\
\hline
\end{tabular}

The data presented in Table 2 show that the analysis of answers from such types of surveys should not be overly generalised. This may lead to incorrect decisions. Analysing the answers of individual groups of employees to individual questions, we may deduce the expected, desirable and actual state of providing the personnel with contract information. Medical personnel know the hospital contracts that have an impact on its operation. 
The answer to this question shows that the management of the studied hospitals is convinced that the personnel know the contracts that impact them. Whereas, according to the statisticians, persons processing the contract data, the employees do not have this information in the studied hospitals. From the answers to this question, we may suggest the following direct actions: notifying the employees about the contracts by providing information both from direct superiors, as well as by placing these data in the hospital's IT system (intranet) and showing employees how to search for them.

\section{Proposed Solutions}

Before we explain why we talk about the role of the DRG system, we should answer a few questions and consider a few important issues. Before explaining why, let's take a look at a few DRG implementations and ask ourselves a few questions. Firstly, think about your controlling experiences over the years. In theory, the use of a DRG system in management seems simple and obvious. In practice, it is much more complex. We may indicate the following limitations: a) organisational structure of a hospital; b) frequently no implemented controlling system; c) hindered conduction of organisational changes; d) no established methodology of DRG system use in hospital management.

Medical personnel decide on the hospital's financial results by making medical decisions, taking the economic aspect into account. Knowledge of the DRG system, which is the basis of contracting with the NHF and of settling and paying for the services, has a deciding impact on the operational effectiveness of the healthcare entity. Organising and conducting medical personnel training is a non-investment route to increasing the operational effectiveness of the hospital. The conducted survey may be considered the first step to organizing the training. A more detailed survey will enable management to determine what type of training various types of medical personnel require. Individualising the assessment of knowledge and modifying the training using an e-learning platform enables one to adapt the contents and training time to suit the needs and capabilities of each medical employee.

The survey shows that in addition to training and motivation, the implementation of the auditing is important for the use of the DRG system in the financial management of the hospital. Establishing the expectations (again) in relation to the DRG system's place in the financial management 
of the hospital should be the initial point in the process of DRG implementation concerning auditing and strategic management of the hospital (redefine what DRG means). Thus, the expectations of the auditing system should be defined according to what services it should deliver and what answers it should provide. Requirements for the auditing system with DRG elements include: a) ease of use of the system; b) automatic data entry (automatic exchange of information between independent IT systems implemented in the hospital), which will save time; c) availability of information; d) supporting the financial decision making process, for example by comparison over time.

Creating a description and presentation of best practices (cases) is one of the ways to propagate solutions tested in one hospital ward to others. Creating a culture of DRG system use in the hospital's financial management will not only improve the financial result, but over a longer time horizon, may also be a factor that ensures a competitive advantage.

\section{Conclusions}

In order to obtain maximum benefits from the DRG system, hospitals should educate their medical personnel on the system in question. Training and the process of solving case studies will lead to an increased consciousness and effectiveness of the decisions taken, by raising the economic awareness of the personnel, and will improve the financial results of the hospitals.

The presented study provides information about the DRG system knowledge possessed by employees in the studied hospitals. The method used and the questions posed may be used for the analysis of the state of DRG system knowledge in every other medical institution. Survey results form the basis for establishing a plan for action, and are a perfect reflection of the situation present in most Polish medical institutions. The proposed actions, intended to increase the knowledge of medical personnel concerning the DRG, may be the initial point to start from as every medical institution prepares its own programme.

A challenge for the hospital management is implementing modern DRG based controlling systems in order to increase the responsibility of medical personnel for the financial results of the institution.

Surveys conducted in 2 hospitals are not enough to form a basis for general conclusions concerning DRG system knowledge. This study is intended to establish the state of knowledge in the surveyed hospitals in order to react, to create a program of appropriate actions, which will result in 
an increased knowledge and will be used in the management process. An active approach to the DRG system is the road to profit (wider gains in profitability).

We have found that the main cause of disappointment in implementing DRG related IT systems is lack of knowledge about DRG, relatively minor investment in training, and an underfunded training budget. One of the obstacles in the implementation of IT systems in hospitals is the gap between the functional capabilities of the implemented solution and knowledge of hospital personnel. Increasing hospital personnel's knowledge and motivation is a low-cost investment to increase ROI from implemented IT systems in hospitals.

In order to maximise the effects while minimising the costs, and to achieve positive effects as rapidly as possible, the training may be conducted in stages. Heads of hospital wards, physicians and medical statisticians have to be trained first. They will be leaders in implementing changes - initiating new actions intended to increase economic effectiveness and to achieve a permanent positive financial result (profit).

For hospital efficiency, it is important to move away from DRG reporting to cost culture. Cost culture can improve the operations of the hospital and drive down the costs. However, it takes some time to develop cost culture in hospitals. Implementation of DRG in hospitals in Poland may not immediately lead to operational efficiencies and cost reductions.

The survey was conducted after obtaining approval from the Bioethics Committee of the Medical University in Eódź and from the Bychawa and Lublin hospital directors.

\section{R E F E R E N C E S}

Busse, R., Geissler, A., Quentin, W., \& Wiley, M. (Eds.). (2011). Diagnosis-Related Groups in Europe. Moving towards transparency, effciency and quality in hospitals. Open University Press. World Health Organization 2011 on behalf of the European Observatory on Health Systems and Policies. Retrieved from http://www.euro.who.int/__data/assets/pdf_file/0004/162265/e96538.pdf.

Charlesworth, A., Davies, A., \& Dixon, J. (2012). Reforming payment for health care in Europe to achieve better value (Research report). Retrieved from: http://www.kpmg.no/arch/img/9826485.pdf.

ECRI Institute. (2012). Electronic Health Records: Is your hospital making all the right connections? in: ECRI Institute's top 10 C-suite watch list. Hospital Technology issues for 2012 (pp. 2-3). Retrieved from: https://www.ecri.org/ Forms/Documents/ECRI_Institute_Top_10_C-Suite_Watch_List_Hospital_ Technology_Issues_for_2012.pdf. 
HealthLeaders Media. (2010). HealthLeaders Media Breakthroughs. HIT that enables quality, efficiency and value. Retrived from http://www.healthleaders media.com.

HealthLeaders Media. (2011). HealthLeaders Media Impact Analysis. ICD-10 skating on thin margins. Retrived from http://www.healthleadersmedia.com.

HOPE - European Hospital and Healthcare Federation. (2006). DRG as a financing tool. Retrieved from http://www.hope.be/05eventsandpublications/docpubli cations/77_drg_report/77_drg_report_2006.pdf.

LaValle, S., Hopkins, M., Lesser, E., Shockley, R., \& Kruschwitz, N. (2010). Analytics: The new path to value. How the smartest organizations are embedding analytics to transform insights into action. IBM Global Business Services. Business Analytics and Optimization Executive Report. MIT Sloan Management Review. Retrieved from http://public.dhe.ibm.com/common/ssi/ecm/ en/gbe03382usen/GBE03382USEN.PDF.

McKenzie, K., Walker, S., \& Lewis, M. (2003). Building the Bridge to E-Coding. In Proceedings Health Information Management Association of Australia Conference 2003, Sydney. Retrived from http://eprints.qut.edu.au/7185/.

Minich-Pourshadi, K. (2011). ICD-10 Puts revenue at risk. HealthLeaders Media Intelligence. Retrieved from http://content.hcpro.com/pdf/content/268585.pdf.

Ustawa z dnia 15 kwietnia 2011 r. o działalności leczniczej. (2011). Dz.U. 2011 vol. 112 item 654. Retrived from http://isap.sejm.gov.pl/DetailsServlet?id= WDU20111120654.

Walker, S., Eynstone-Hinkins, J., \& Schmider, A. (2011). Implementation of ICD11 perspectives from the Australian Bureau of Statistics. In R. Jakob (Ed.), World Health Organization Family of International Classifications Network Meeting, 29 October - 5 November 2011, Southern Sun, Cape Town, South Africa. Retrived from http://eprints.qut.edu.au/46662/.

Walker, S., \& Waller, G.. (2010). Experiences in training ICD-10 trainers. In R. Jakob (Ed.), Proceedings of the WHO-FIC Annual Meeting, Toronto 2010, World Health Organization. Retrieved from http:/eprints.qut.edu.au/46664/.

Wike, M., \& Grube, R. (2010). Pharmaco-economic evaluation of antibiotic therapy strategies in DRG-based healthcare systems - a new approach. European Journal of Medical Research, 15, 564-570.

Wike, M., Grube, R., \& Bodmann, K. (2011). The use of a standardized PCTalgorithm reduces costs in intensive care in septic patients - A DRG-based simulation model. European Journal of Medical Research, 16, 543-548. 